\title{
Ions Released from Dental Amalgams in Contact with Titanium
}

\author{
Shi-Duk LIM, Yukyo TAKADA ${ }^{1}$, Kyo-Han KIM ${ }^{2}$ \\ and Osamu OKUNO ${ }^{1}$ \\ Department of Dental Technology, Daegu Polytechnic College \\ 395, 3-Manchon-Dong, Susung-Gu, Daegu 706-711, Korea \\ ${ }^{1}$ Division of Dental Biomaterials, Department of \\ Oral Rehabilitation and Materials Science, \\ Tohoku University Graduate School of Dentistry \\ 4-1, Seiryo-machi, Aoba-ku, Sendai 980-8575, Japan \\ ${ }^{2}$ Department of Dental Materials College of Dentistry, \\ Kyungpook National University \\ 2-101, Dong In-Dong, Daegu, Korea
}

Received October 15, 2002/Accepted December 25, 2002

\begin{abstract}
The ions released from conventional and high-copper amalgams in contact with titanium were quantitatively analyzed in a $0.9 \% \mathrm{NaCl}$ solution at $37^{\circ} \mathrm{C}$ when the surface area ratio of titanium/amalgam was set up as $1 / 10,1 / 1$, or $10 / 1$. The corrosion potentials of the amalgams and titanium were measured under the same conditions. Surface analyses on the amalgams were also employed using SEM with WDS. Though the potential of the conventional amalgam was always lower than that of titanium, that of the high-copper amalgam was reversed during the early stage of immersion and remained lower. When the surface area ratio of titanium grew at $10 / 1$, tin and copper ions released from the conventional and high-copper amalgam, respectively, increased significantly compared with those of each amalgam that was not in contact with titanium. The galvanic corrosion in such a large surface area of titanium possibly led to the heavy corrosion of the amalgams.
\end{abstract}

Key words: Galvanic corrosion, Dental amalgam, Titanium

\section{INTRODUCTION}

Recent dental treatments using various metals often result in the coexistence of multiple kinds of metal in the oral cavity. The coexistence of the dissimilar metals often brings about the risk of significantly increasing the release of ions from the metals with concomitant galvanic corrosion. Even if a metal is corrosion-resistant in single use, it might release noxious ions when placed in contact with other metals. From the viewpoint of safety to human tissue, a decrease in released ions is more important than corrosion damage, since released ions predictably cause allergic reactions. Ions released from dental amalgams can be particularly caustic. They contain toxic elements, such as mercury, and should be thoroughly investigated for galvanic corrosion.

Many studies have examined galvanic corrosion ${ }^{1-4)}$ in conjunction with dental amalgams in contact with gold alloys, since the mercury in dental amalgams results in amalgamation with elements such as gold and copper, which are the main elements 
in the gold alloys. In addition, it has been reported that the combination of gold alloys and conventional amalgams accelerated to corrode the $\gamma_{2}$ phase ${ }^{4)}$ and increased the amount of copper and tin ions released from the amalgams ${ }^{5}$.

On the other hand, a few studies on galvanic corrosion between dental amalgams and titanium, which focused on the corrosion potential and galvanic current. ${ }^{6.7)}$ recently have been reported. Yamaoka ${ }^{8)}$ calculated the galvanic current between a conventional amalgam and titanium using anodic and cathodic polarization curves and revealed that contact with titanium accelerates the corrosion of the amalgam since the galvanic current density showed little change on titanium even when the surface area of titanium increased 10 times larger than that of the amalgam. Ravnholt ${ }^{9)}$ measured the galvanic current densities between amalgams and titanium in a $1 \%$ $\mathrm{NaCl}$ solution, which simulated the environment in the oral cavity, or in vivo and showed that the conventional and high-copper amalgams in contact with titanium preferentially corroded as anodes. Johansson and Bergmanet ${ }^{10)}$ measured the galvanic current densities of amalgams in contact with titanium in a $0.9 \% \mathrm{NaCl}$ solution and revealed that the corrosion potential and the galvanic current were always anodic on the conventional amalgam. On a high-copper amalgam with titanium, the galvanic current was also anodic after sufficient time passed to maintain a steady state, except during the early stage of immersion. Horasawa et al. ${ }^{11}$ examined the effects of the surface area ratios of titanium/amalgam in a range of $1 / 1-6 / 1$ on the corrosion potential and the galvanic current density on the high-copper amalgam in contact with titanium in artificial saliva at $37^{\circ} \mathrm{C}$. They confirmed that such a combination between the amalgam and titanium did not have much effect on the galvanic corrosion since the galvanic current densities were very small, within orders of $10^{-8}$ $\mathrm{A} / \mathrm{cm}^{2}$, even if the titanium surface area increased.

The corrosion potential or the galvanic current has established that the amalgams kept in the anodic situation appear to corrode preferentially in combinations of amalgams and titanium. Since the amalgams remain in an oral cavity for a long time, ions released from them can have a major effect on human tissues. Therefore, the kinds and amounts of released ions, which have the potential to cause metal allergies, must be carefully evaluated.

In this study, the ions released from a conventional and high-copper amalgam in contact with titanium at a surface area ratio of titanium/amalgam at 1/10, $1 / 1$, and $10 / 1$ were qualitatively and quantitatively analyzed after immersion in a $0.9 \% \mathrm{NaCl}$ solution at $37^{\circ} \mathrm{C}$ for 7 days. Furthermore, the corrosion potentials were measured, and the corrosion products were analyzed relative to their effects on the amalgam surfaces using a scanning electron microscope (SEM) with wavelength dispersive Xray spectroscopy (WDS). The objective was to investigate the effects of the surface area ratio on the released ions and explain the galvanic corrosion mechanism between the amalgams and titanium. 


\section{MATERIALS AND METHODS}

\section{Materials}

A conventional amalgam (Hi Atomic M; GC Co., Ltd., Tokyo, Japan) and a highcopper amalgam (Lumi Alloy; GC Co., Ltd., Tokyo, Japan) were selected, and their compositions are shown in Table 1. After the conventional amalgam and the highcopper amalgam powders were mixed with mercury in the mass ratio of powder/mercury of $1 / 0.75$ and 1/0.83 designated by the company, respectively, columnar amalgam specimens with a diameter of $4 \mathrm{~mm}$ and a length of $10 \mathrm{~mm}$ were prepared in conformity with ANSI/ADA Specification No.1 for Alloys for Dental Amalgam. These specimens were used for an elution test and other experiments after being kept at $37^{\circ} \mathrm{C}$ for 7 days. For the corrosion potential measurement and the surface analysis, half-size specimens were made of the columnar amalgam cut in the median plane in a longitudinal direction and buried with an electrical lead in epoxy resin. Titanium specimens were squarely cut off at a size of $10-30 \mathrm{~mm}$ from a rolled titanium sheet (Grade 1; Kobe Steel Co., Ltd.) with a thickness of $1 \mathrm{~mm}$.

\begin{tabular}{llcccc} 
Table 1 Composition of amalgam alloys (by manufacturers) \\
\hline Amalgam alloy type & Product name & $\mathrm{Ag}$ & $\mathrm{Sn}$ & $\mathrm{Cu}$ & Rest \\
\hline Conventional & Hi-Atomic $\mathrm{M}$ & 70.0 & 27.0 & 2.0 & 1.0 \\
High copper & Lumi Alloy & 55.0 & 29.0 & 16.0 & - \\
\hline
\end{tabular}

\section{Corrosion potential}

After a $0.9 \% \mathrm{NaCl}$ solution was sufficiently saturated with oxygen by bubbling with air, the dissolved oxygen concentration was confirmed using a dissolved oxygen meter (DO-1/1P; TOA Denpa, Co., Ltd.), and maintained at about $6 \mathrm{mg} / \mathrm{l}$. Since the saturated dissolved oxygen leads to increase the rate of a cathodic reaction, the corrosion with a sufficient anodic reaction is expected to proceed. The corrosion potential of each specimen versus a reference electrode $(\mathrm{Ag} / \mathrm{AgCl})$ was recorded in a $0.9 \%$ $\mathrm{NaCl}$ solution at $37^{\circ} \mathrm{C}$ for 7 days. Before testing, each specimen surface was polished with 180-800 grit silicon carbide papers and then ultrasonically cleaned with distilled water for $1 \mathrm{~min}$. After drying, it was wiped with ethanol, and potential measurements were started using a voltage follower amplifier with a $\mathrm{x}$-t recorder (EPR-152A, TOA Denpa, Co., Ltd.). The amplifier composed of the OP amplifier (AD544KH, Analog Devices, Co., Ltd.), which had an extremely large input impedance $\left(>10^{11} \Omega\right)$ and an error range within less than $0.1 \mathrm{mV}$, was specially made to order. Statistical analyses of the corrosion potentials $(n=3)$ at $12 \mathrm{hr}, 24 \mathrm{hr}, 48 \mathrm{hr}$, and $168 \mathrm{hr}$ (7 days) were performed using ANOVA/Scheffe's tests at a significance level of $p=0.05$.

\section{Elution test}

While the amalgam surface was maintained at near $1.5 \mathrm{~cm}^{2}$, the columnar amalgam was joined to the titanium sheet with a short electrical lead after the titanium 
surface had been adjusted with enamel resin so that the surface area ratios of titanium/amalgam $\left(\mathrm{S}_{\mathrm{Ti}} / \mathrm{S}_{\mathrm{A}}\right)$ were $1 / 10,1 / 1$, and $10 / 1$. (The "surface area ratios of titanium/amalgam" are hereafter referred to as " $\mathrm{S}_{\mathrm{Ti}} / \mathrm{S}_{\mathrm{A}}$.") The amalgam specimen was placed in the center of the titanium sheet, and the distance between the amalgam specimen and the titanium sheet was set at $5 \mathrm{~mm}$. Other pretreatments were similar to the specimen used for the corrosion potential. After each jointed specimen, including unjointed one, was immersed in a $0.9 \% \mathrm{NaCl}$ solution with saturated dissolved oxygen $(6 \mathrm{mg} / \mathrm{l})$ at $37^{\circ} \mathrm{C}$ for 7 days, the solution removed from the specimen was qualitatively and quantitatively analyzed using an inductively coupled plasma atomic emission spectrometry analyzer (ICP) (IRIS_AP; Nippon Jarrell-Ash Co., Ltd., Tokyo, Japan). The mass-per-unit area of released ions was converted from the detected ion concentration. Statistical analyses of the released ions $(n=5)$ were also performed using ANOVA/Scheffe's tests at a significance level of $\mathrm{p}=0.05$.

\section{Surface analysis}

Specimens for surface analyses were prepared by coupling the amalgam and titanium specimens for the corrosion potential with $\mathrm{S}_{\mathrm{T}} / \mathrm{S}_{\mathrm{A}}$ of $1 / 10,1 / 1$, and $10 / 1$. After immersing under the same conditions, the surface morphology was observed using a scanning electron microscope (SEM) with wavelength dispersive X-ray spectroscopy (WDS) (JXA 8900R; JEOL, Tokyo, Japan). The corrosion products and distribution of elements on the amalgam surface were qualitatively and quantitatively analyzed. Statistical analyses of the distribution of elements $(n=3)$ were performed using ANOVA/Scheffe's tests at a significance level of $\mathrm{p}=0.05$.

\section{RESULTS}

\section{Corrosion potential}

The changes of corrosion potentials on the conventional amalgam, the high-copper amalgam, and titanium in a $0.9 \% \mathrm{NaCl}$ solution with saturated dissolved oxygen at $37^{\circ} \mathrm{C}$ are summarized in Fig. 1. Each profile is shown as a region of the potential in the figure. The potentials on titanium immediately rose with time from the low potentials after the immersion, and an increase above $0.15 \mathrm{~V}$ was observed after $24 \mathrm{hr}$. Thereafter, the potentials gradually increased with time. Although the potentials on the conventional amalgam dropped slightly during the early stage of immersion, they rapidly recovered and rose slightly with time. The conventional amalgam always showed significantly lower $(\mathrm{p}<0.05)$ potentials than titanium for $168 \mathrm{hr}$ ( 7 days), and the differences in the potentials between the conventional amalgam and titanium were about $0.2 \mathrm{~V}$ except in the early stage of immersion. However, the high-copper amalgam showed relatively higher potentials than the others for $24 \mathrm{hr}$; the potentials suddenly dropped from 24 to $40 \mathrm{hr}$ and remained stable thereafter. The potentials on the high-copper amalgam were significantly higher $(p<0.05)$ than those of titanium for $12 \mathrm{hr}$, but no significant difference $(\mathrm{p}>0.05)$ was observed between 24 and $48 \mathrm{hr}$. In contrast, they were significantly lower $(p<0.05)$ than those of titanium over 48 


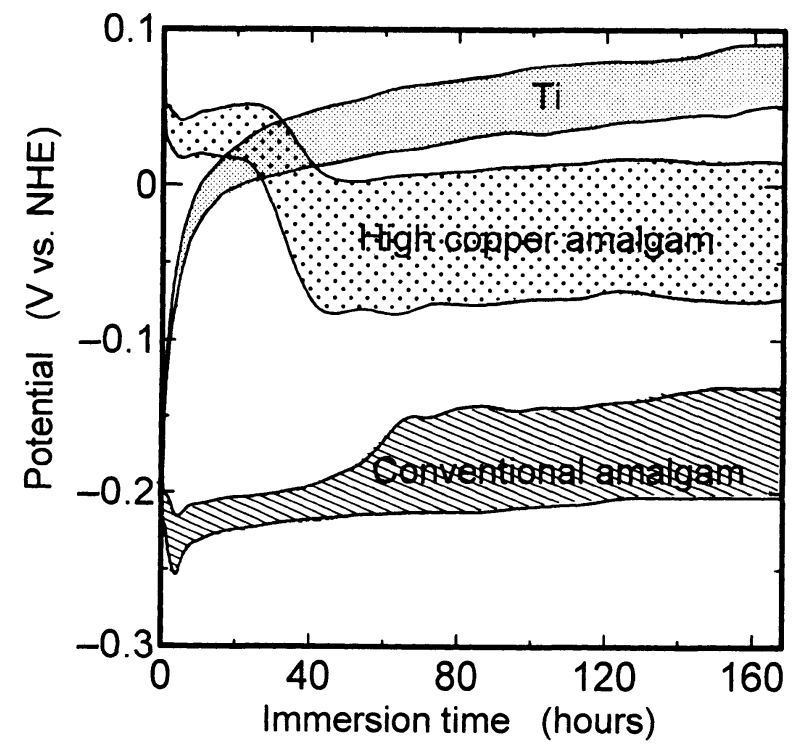

Fig. 1 Profiles of corrosion potentials versus immersion time on the conventional amalgam, the high copper amalgam and titanium in $0.9 \%$ $\mathrm{NaCl}$ solution with saturated dissolved oxygen at $37^{\circ} \mathrm{C}$.

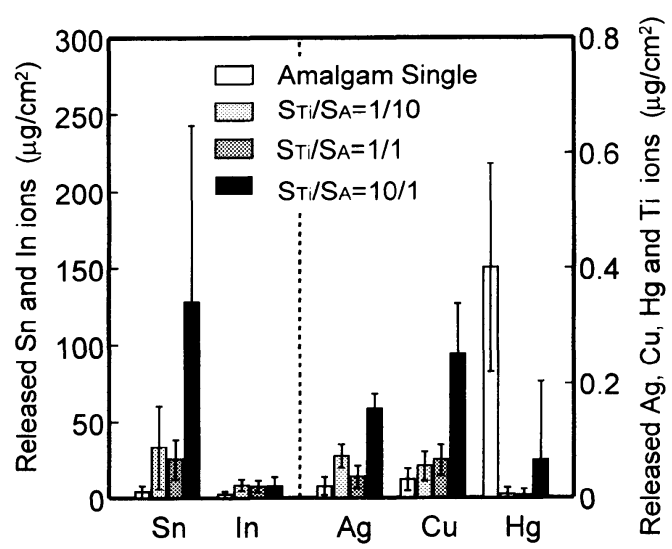

Fig. 2 Ions released from the conventional amalgam in contact with titanium changing the surface area ratio of $\mathrm{S}_{\mathrm{Ti}} / \mathrm{S}_{\mathrm{A}}$ in $0.9 \% \mathrm{NaCl}$ solution with saturated dissolved oxygen at $37^{\circ} \mathrm{C}$ during 7 days.

(Vertical lines reveal the standard deviation.)



Fig. 3 Ions released from the high copper amalgam in contact with titanium changing the surface area ratio of $\mathrm{S}_{\mathrm{Ti}} / \mathrm{S}_{\mathrm{A}}$ in $0.9 \% \mathrm{NaCl}$ solution with saturated dissolved oxygen at $37^{\circ} \mathrm{C}$ during 7 days.

(Vertical lines reveal the standard deviation.) 
hr. The potentials on the high-copper amalgam were always significantly higher $(\mathrm{p}<0.05)$, beyond $0.05 \mathrm{~V}$, than those on the conventional amalgams for $168 \mathrm{hr}$.

\section{Released ions}

The released ions from the conventional amalgam not in contact with and in contact with titanium at $\mathrm{S}_{\mathrm{Ti}} / \mathrm{S}_{\mathrm{A}}=1 / 10,1 / 1$, and $10 / 1$ in a $0.9 \% \mathrm{NaCl}$ solution with saturated dissolved oxygen at $37^{\circ} \mathrm{C}$ are summarized in Fig. 2. The conventional amalgam not in contact with titanium mainly released indium and tin ions at $2.3 \mu \mathrm{g} / \mathrm{cm}^{2}$ and $4.1 \mu \mathrm{g} /$ $\mathrm{cm}^{2}$, respectively, including slight amounts of silver, copper, and mercury ions. When the conventional amalgam made contact with titanium at $\mathrm{S}_{\mathrm{Ti}_{\mathrm{i}}} / \mathrm{S}_{\mathrm{A}}=1 / 10$ or $1 / 1$, each amount of released indium and tin ions increased $(\mathrm{p}<0.05)$ about 2 -fold and 5 -fold, respectively, compared with those of the amalgam not in contact with titanium, regardless of the surface area ratio. When the surface area ratio was $10 / 1$, the amount of released indium ions doubled $(p<0.05)$ and that of released tin ions increased markedly, 50 to -100 times $(\mathrm{p}<0.05)$. However, while mercury ions were released at $0.4 \mu \mathrm{g} / \mathrm{cm}^{2}$ from the amalgam not in contact with titanium, only a few mercury ions below $0.0049-0.065 \mu \mathrm{g} / \mathrm{cm}^{2}$ could be detected in contact with titanium at any surface area ratio.

The released ions from the high-copper amalgam not in contact with and in contact with titanium at $\mathrm{S}_{\mathrm{Ti}} / \mathrm{S}_{\mathrm{A}}=1 / 10,1 / 1$, and $10 / 1$ in a $0.9 \% \mathrm{NaCl}$ solution with saturated dissolved oxygen at $37^{\circ} \mathrm{C}$ are also summarized in Fig. 3. The high-copper amalgam not in contact with titanium released the largest amount of copper ions among those of other ions $(p<0.05)$. The amounts of released ions were lined up in abounding order of copper, tin, mercury, and silver. When the high-copper amalgam made contact with titanium, the amounts of released copper ions decreased to $1 / 6$ and $1 / 3$ at $\mathrm{S}_{\mathrm{Ti}} / \mathrm{S}_{\mathrm{A}}=1 / 10$ and $1 / 1$, respectively, compared with those of the amalgam not in contact with titanium. However, the copper ions increased markedly to greater than 15 -to 20 times at $\mathrm{S}_{\mathrm{Ti}} / \mathrm{S}_{\mathrm{A}}=10 / 1 \quad(\mathrm{p}<0.05)$. The amount of tin ions increased gradually when the surface area ratio of titanium grew and reached 5 times at $\mathrm{S}_{\mathrm{Ti}} / \mathrm{S}_{\mathrm{A}}=10 / 1 \quad(\mathrm{p}<0.05)$. On the other hand, the contact with titanium also reduced the release of the mercury ions from the amalgam at any surface area ratio below $1 / 5$ despite the release of mercury ions of $2.4 \mu \mathrm{g} / \mathrm{cm}^{2}$, which were not in contact with titanium.

\section{Surface analysis}

SEM images of the conventional amalgam before and after immersion in a $0.9 \%$ $\mathrm{NaCl}$ solution with saturated dissolved oxygen at $37^{\circ} \mathrm{C}$ for 7 days are shown in Fig. 4. After immersion, a number of corrosion products, which were similar in appearance to a rash, were observed on the conventional amalgam surfaces. More results of corrosion were evident when the surface area ratio of titanium increased. These corrosion products evenly adhered throughout on the conventional amalgam surfaces.

The distributions of elements on the conventional amalgam surfaces shown in Fig. 4 were quantitatively analyzed using WDS and are shown in Fig. 5. A qualitative 



(a) Before
(b) Amalgam Single
(c) $\mathrm{S}_{\mathrm{Ti}} / \mathrm{S}_{\mathrm{A}}=10 / 1$

Fig. 4 SEM images of the conventional amalgam surface in contact with titanium changing the surface area ratio of $\mathrm{S}_{\mathrm{Ti}} / \mathrm{S}_{\mathrm{A}}$ before and after immersion in $0.9 \% \mathrm{NaCl}$ solution with saturated dissolved oxygen at $37^{\circ} \mathrm{C}$ during 7 days.

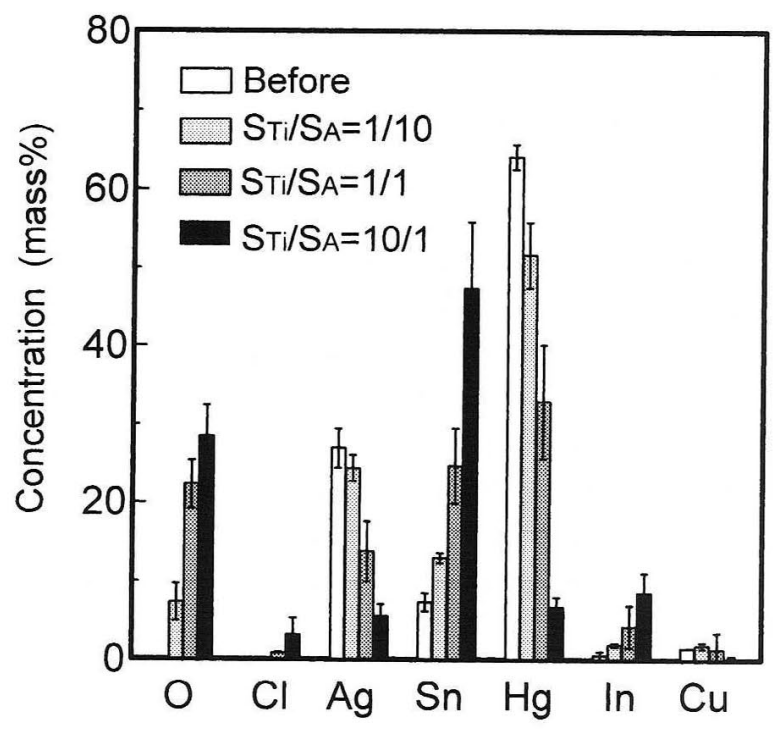

Fig. 5 Distributions of each element on the conventional amalgam surface in contact with titanium changing the surface area ratio of $\mathrm{S}_{\mathrm{Ti}} /$ $\mathrm{S}_{\mathrm{A}}$ before and after immersion in $0.9 \% \mathrm{NaCl}$ solution with saturated dissolved oxygen at $37^{\circ} \mathrm{C}$ during 7 days.

(Vertical lines reveal the standard deviation.) 
analysis of the corrosion products on the conventional amalgam surfaces after immersion suggested that the products consisted of tin, oxygen, and chlorine. When the conventional amalgam contacted with titanium, the growth of the surface area ratio of titanium caused the concentrations of oxygen, tin, and indium to increase on the surfaces. The concentrations of these elements at $\mathrm{S}_{\mathrm{Ti}} / \mathrm{S}_{\mathrm{A}}=10 / 1$ were significantly greater $(p<0.05)$ than those before immersion. Silver and mercury tended to decrease on the surfaces as the surface area ratio of titanium grew, and their concentrations at $\mathrm{S}_{\mathrm{Ti}} / \mathrm{S}_{\mathrm{A}}=1 / 1$ and $10 / 1$ were significantly less $(\mathrm{p}<0.05)$ than those at $\mathrm{S}_{\mathrm{Ti}} /$ $\mathrm{S}_{\mathrm{A}}=1 / 10$ and before immersion.

SEM images of the high-copper amalgam before and after immersion in a $0.9 \%$ $\mathrm{NaCl}$ solution with saturated dissolved oxygen at $37^{\circ} \mathrm{C}$ for 7 days are shown in Fig. 6. No remarkable changes were found on the high-copper amalgam surfaces in Fig. 6 (a) and (b) whether they were in contact with titanium. However, in the composition image in Fig. 6(c), there are some dark areas in the vicinity of small pits on the surface at $\mathrm{S}_{\mathrm{T}} / \mathrm{S}_{\mathrm{A}}=10 / 1$ after immersion. Though the dark areas were small on the surface of the amalgam that was not in contact with titanium, they appeared to extend widely when the surface area ratio of titanium increased.

The dark areas and matrices on the high-copper amalgam surfaces were quantitatively analyzed using WDS. Distributions of elements on the dark areas and the matrices are shown in Fig. 7 and Fig. 8, respectively. The matrices had a composition similar to that of the amalgam before immersion regardless of the surface area ratio of titanium $(p>0.05)$. However, oxygen and tin distributed on the dark areas were significantly increased $(\mathrm{p}<0.05)$ at any surface area ratio, and silver, mercury, and copper significantly decreased $(\mathrm{p}<0.05)$, except at $\mathrm{S}_{\mathrm{Ti}} / \mathrm{S}_{\mathrm{A}}=1 / 10$, compared with the composition before immersion.

\section{DISCUSSION}

\section{Corrosion and released ions of amalgams}

It is commonly known that conventional amalgams are composed of the remaining particles of the $\beta$ and the $\gamma$ phases $(\mathrm{Ag}-\mathrm{Sn})$, the $\gamma_{1}$ phase $\left(\mathrm{Ag}_{2} \mathrm{Hg}_{3}\right)$, the $\gamma_{2}$ phase $\left(\mathrm{Sn}_{8} \mathrm{Hg}\right)$, and the $\varepsilon$ phase $\left(\mathrm{Cu}_{3} \mathrm{Sn}\right)^{4,12,13)}$. Though both the remaining particles of the $\beta$ and the $\gamma$ phases and the $\gamma_{1}$ phase are reported to be stable in the oral cavity, ${ }^{14)}$ the $\gamma_{2}$ phase is thermodynamically unstable compared with the other phases in corrosive environments, such as the oral cavity ${ }^{4,14,15)}$. Many studies have reported that the $\gamma_{2}$ phase, which sometimes precipitated near the margin of the restoration, preferentially corroded and degraded the mechanical properties ${ }^{4,16)}$. According to Fig. 2 , tin ions appeared to preferentially dissolve from the $\gamma_{2}$ phase, since relatively larger amounts of tin $\left(4.1 \mu \mathrm{g} / \mathrm{cm}^{2}\right)$ and mercury ions $\left(0.4 \mu \mathrm{g} / \mathrm{cm}^{2}\right)$ than of other ions (except indium ions) were detected. The amount of released mercury ions, which have a potential to cause metal allergies ${ }^{17,18)}$, was $10 \%$ lower than that of released tin ions. As the sum of tin and mercury ions was smaller than that of copper and zinc ions released from type-4 gold alloys or gold-silver-palladium alloys ${ }^{19-22)}$, tin and 


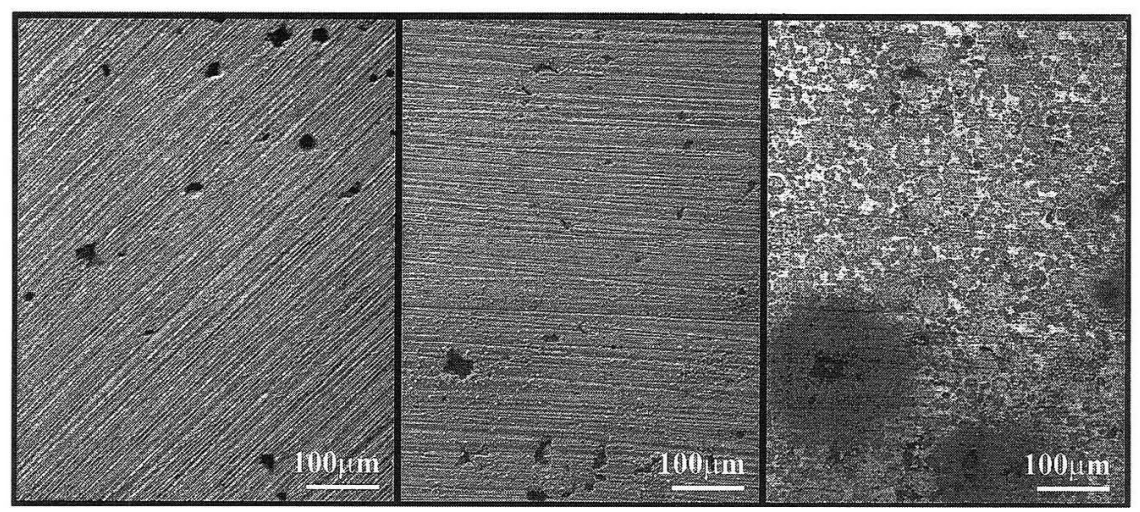

(a) Before

(SEM image) (b) $\mathrm{S}_{\mathrm{Ti}} / \mathrm{S}_{\mathrm{A}}=10 / 1$

(SEM image) (c) $\mathrm{S}_{\mathrm{T}} / \mathrm{S}_{\mathrm{A}}=10 / 1$

(Composition image)

Fig. 6 SEM and composition images of the high copper amalgam surface in contact with titanium changing the surface area ratio of $\mathrm{S}_{\mathrm{Ti}} / \mathrm{S}_{\mathrm{A}}$ before and after immersion in $0.9 \% \mathrm{NaCl}$ solution with saturated dissolved oxygen at $37^{\circ} \mathrm{C}$ during 7 days.

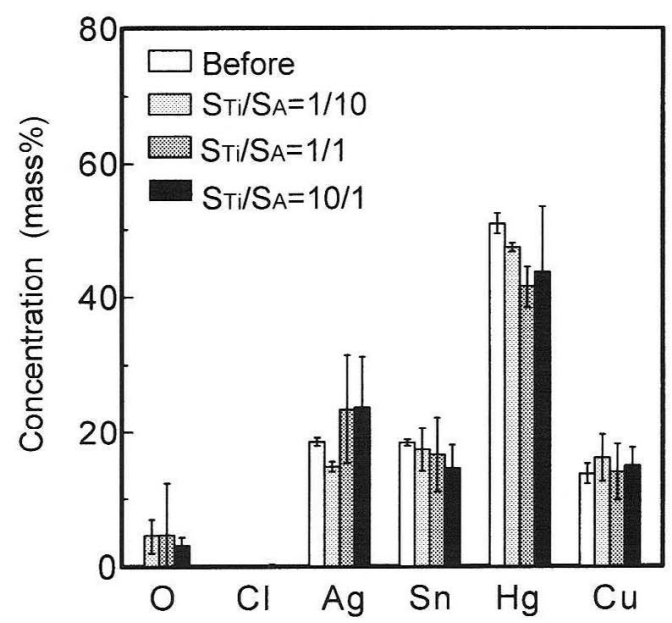

Fig. 7 Distributions of each element on the high copper amalgam surface (Matrix) in contact with titanium changing the surface area ratio of $\mathrm{S}_{\mathrm{Ti}} / \mathrm{S}_{\mathrm{A}}$ before and after immersion in $0.9 \%$ $\mathrm{NaCl}$ solution with saturated dissolved oxygen at $37^{\circ} \mathrm{C}$ during 7 days. (Vertical lines reveal the standard deviation.)

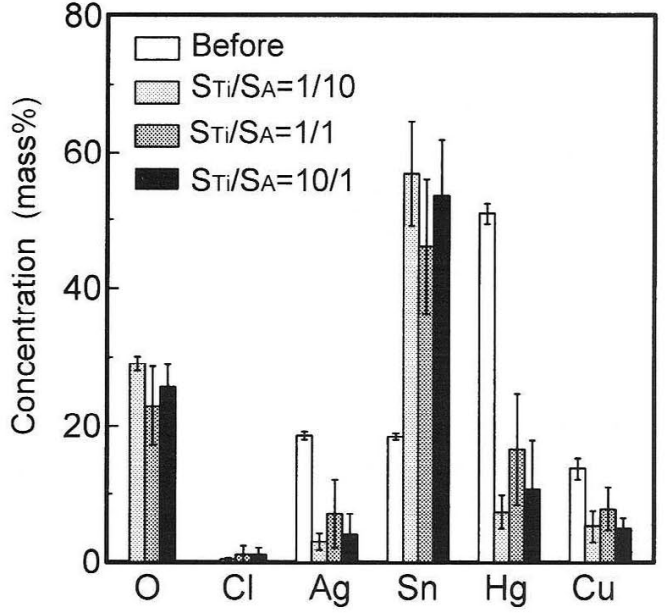

Fig. 8 Distributions of each element on the high copper amalgam surface (Dark area) in contact with titanium changing the surface area ratio of $\mathrm{S}_{\mathrm{Ti}} / \mathrm{S}_{\mathrm{A}}$ before and after immersion in $0.9 \%$ $\mathrm{NaCl}$ solution with saturated dissolved oxygen at $37^{\circ} \mathrm{C}$ during 7 days. (Vertical lines reveal the standard deviation.) 
mercury ions appeared relatively resistant to being released from the conventional amalgam not in contact with titanium.

High-copper amalgams without the $\gamma_{2}$ phase usually have the remaining particles of the $\beta$ or the $\gamma$ phases, the $\gamma_{1}$ phase, the $\varepsilon$ phase, and the $\eta^{\prime}\left(\mathrm{Cu}_{6} \mathrm{Sn}_{5}\right)$ phase $\mathrm{p}^{13,23)}$. The $\eta$ ' phase is also thermodynamically unstable among the other phases in highcopper amalgams $\mathrm{s}^{4,14,15)}$. Ogletree and $\mathrm{Marek}^{24)}$ reported that mercury destabilized the protective passive film on the $\eta^{\prime}$ phase, making the phase more susceptible to corrosion in the oral environment. As shown in Fig. 3, copper ions were released in the largest amount $\left(24.4 \mu \mathrm{g} / \mathrm{cm}^{2}\right)$; next were tin ions $\left(5.8 \mu \mathrm{g} / \mathrm{cm}^{2}\right)$ in the high-copper amalgam not in contact with titanium. Since the $\varepsilon$ phase composed of copper and tin shows a relatively higher corrosion potential than the other phase ${ }^{25)}$, most of the released copper ions appeared to be derived from the ' $\eta^{\prime}$ phase. Consequently, the $\gamma_{2}$ and the $\eta$ ' phases possibly dissolved preferentially on the conventional and the high-copper amalgam, respectively, as in previous studies.

\section{Galvanic corrosion between the conventional amalgam and titanium}

The potentials of the conventional amalgam not in contact with titanium slightly dropped during the early stage of immersion but immediately recovered and tended to increase gently thereafter, as shown in Fig. 1. Covering the amalgam surface with tin oxide film ${ }^{4,26,27)}$ probably caused the potentials to stop dropping. In other words, although the corrosion of the $\gamma_{2}$ phase with a relatively high corrosion rate caused the potential to drop immediately following immersion, the tin oxide film which formed with the released tin ions on the amalgam surface reduced the corrosion rate and caused the potential to gradually increase. On the other hand, the corrosion potentials of titanium after passivation rose to about $0.2 \mathrm{~V}$ higher than those of the amalgam. The anodic potential of titanium is expected to accelerate the corrosion rate of the amalgam when titanium contacts with the amalgam.

As shown in Fig. 4, the quantity of corrosion products deposited on the amalgam surface in contact with titanium tended to increase as the surface area ratio of titanium grew. When the corrosion products were qualitatively and quantitatively analyzed using WDS, tin, oxygen, and chlorine concentrated on the products. A large quantity of corrosion products (including tin oxide and tin chloride) on the amalgam surface in contact with titanium at $\mathrm{S}_{\mathrm{Ti}} / \mathrm{S}_{\mathrm{A}}=10 / 1$ suggested that contact with a large surface area ratio of titanium accelerated the corrosion of the amalgams. When the amalgam surface was quantitatively analyzed by WDS, the distributions of tin, oxygen, and chlorine increased, but those of silver and mercury decreased as the surface area ratio of titanium increased (Fig.5). Since a large surface area ratio of titanium increases the corrosion potential and the galvanic current on the amalgam, the acceleration of the anodic reaction increases the amount of released tin ions. Accordingly, the large amount of released tin ions possibly formed the tin oxide and chloride that thickly covered the amalgam surface. On the other hand, the decrease in the distributions of silver and mercury on the surface appeared to be caused by thick tin oxide and chloride films preventing the detection of these elements. The 
thickness of the films at $\mathrm{S}_{\mathrm{Ti}} / \mathrm{S}_{\mathrm{A}}=10 / 1$ might be greater than $1 \mu \mathrm{m}$. This was demonstrated by the fact that electron beams of SEM cannot reach the underlying amalgam surface, as elements other than tin, oxygen, and chlorine were hardly detected.

When the amalgams contacted with titanium at any surface area ratio, the amounts of released mercury ions markedly decreased compared with those of the amalgam not in contact with titanium. The released mercury ions appeared to hardly adsorb on the walls of the elution test bottles and did not appear to be deposited in the solution. This was demonstrated by the finding that mercury ions were detected in the amalgam that was not in contact with titanium under the same condition. The mercury ions are expected to mainly dissolve from the $\gamma_{2}$ phase, which is susceptible to corrosion. If chloride ions attack the $\gamma_{2}$ phase, the phase dissolves according to: ${ }^{28,29)}$

$$
8 \mathrm{Sn}_{7} \mathrm{Hg}+21 \mathrm{O}_{2}+42 \mathrm{H}_{2} \mathrm{O}+28 \mathrm{Cl}^{-} \rightarrow 14 \mathrm{Sn}_{4}(\mathrm{OH})_{6} \mathrm{Cl}_{2}+8 \mathrm{Hg}
$$

This reaction indicates that mercury contained in the $\gamma_{2}$ phase formed mercury metal. Although a part of the mercury metal changes to oxides or chlorides, the rest evaporates ${ }^{30,31)}$. If the reduction reaction between mercury ions and mercury metal occurs on the surface of both the amalgam and titanium since titanium is mainly in charge of cathodic reactions, the amalgam with titanium will have a larger reaction area than the amalgam without titanium. Takada et al. ${ }^{32)}$ reported that immersing a titanium sheet decreased the concentration of mercury ions in $0.9 \% \mathrm{NaCl}$ solution containing $1 \mathrm{ppm}$ or $10 \mathrm{ppm}$ of mercury ions. Although the titanium surfaces in contact with the amalgams were quantitatively analyzed using WDS, some tin but no mercury could be found at any surface area ratios. Mercury would have evaporated or would exist under the thick tin oxide film even if mercury had adsorbed on the titanium surfaces.

The tin oxide film surely played a role to suppress the elution of ions when the amalgam was not in contact with titanium. However, there is confirmed risk that the contact with titanium at such a large surface area ratio of titanium of $\mathrm{S}_{\mathrm{Ti}} / \mathrm{S}_{\mathrm{A}}=$ $10 / 1$ extremely reduces the effect of suppression.

\section{Galvanic corrosion between high-copper amalgam and titanium}

As shown in Fig. 1, the corrosion potentials of the high-copper amalgam not in contact with titanium were significantly higher than those of titanium for $12 \mathrm{hr}$ after immersion. In this case, the amalgam plays the role of a cathode, and titanium with a cathodic potential suppresses the corrosion of the amalgam contacted with titanium. On the other hand, the corrosion potentials of the amalgam and titanium were reversed after $48 \mathrm{hr}$, and the potentials of the amalgam were kept significantly lower than those of titanium. The anodic potential of titanium is expected to accelerate the corrosion rate of the amalgam when titanium contacts with the amalgam.

Figure 3 shows that the amount of copper ions which were possibly released from the $\eta^{\prime}$ phase was largest in the amalgam that was not in contact with titanium. However, the amount of copper ions decreased in contact with titanium at 
$\mathrm{S}_{\mathrm{Ti}} / \mathrm{S}_{\mathrm{A}}=1 / 10$ and $1 / 1$. This decrease in the amount of copper ions would be caused by the suppression of corrosion of the $\eta^{\prime}$ phase, since titanium with a cathodic potential lowered the corrosion potential of the amalgam in contact with titanium at $\mathrm{S}_{\mathrm{Ti}} / \mathrm{S}_{\mathrm{A}}=$ $1 / 10$ and $1 / 1$ in the early stage of immersion. Titanium should also have suppressed the corrosion of the $\eta^{\prime}$ phase at $\mathrm{S}_{\mathrm{Ti}} / \mathrm{S}_{\mathrm{A}}=10 / 1$. Since a large value of the galvanic current probably flowed between the amalgam and titanium after reversal of the corrosion potentials, the titanium with anodic potential extremely accelerated the corrosion of the $\eta$ ' phase. Consequentially, the effect in which titanium suppressed the corrosion of the $\eta^{\prime}$ phase during the early stage of immersion was increasingly low, and the amount of released copper ions increased at $\mathrm{S}_{\mathrm{Ti}} / \mathrm{S}_{\mathrm{A}}=10 / 1$.

The amount of released tin ions increased in contact with titanium as the surface area ratio of titanium grew. If tin ions are mainly released from the $\eta$ ' phase, the potential at the dissolution of tin from the $\eta^{\prime}$ phase appears to be much lower than that of copper. Probably, the dissolution potential of tin is always lower than the corrosion potential of the amalgam in contact with titanium independent of the immersion time. Even when titanium lowered the corrosion potential of the amalgam during the early stage of immersion, the corrosion potential stayed above the dissolution potential of tin. Accordingly, tin continuously dissolved, depending on the surface area ratio of $\mathrm{S}_{\mathrm{Ti}} / \mathrm{S}_{\mathrm{A}}$.

The composition image shown in Fig. 6(c) had some dark areas in the vicinity of small pits on the surface at $\mathrm{S}_{\mathrm{T}} / \mathrm{S}_{\mathrm{A}}=10 / 1$ after immersion. The matrices, except the dark areas, had a composition similar to that of the amalgam before immersion regardless of the surface area ratio of titanium $(p>0.05)$. However, oxygen and tin on the dark areas significantly increased $(\mathrm{p}<0.05)$ at any surface area ratio, and silver, mercury, and copper significantly decreased $(\mathrm{p}<0.05)$, except at $\mathrm{S}_{\mathrm{Ti}} / \mathrm{S}_{\mathrm{A}}=1 / 10$, as shown in Fig. 8. These results suggest that the vicinity of small pits on the highcopper amalgam selectively corroded and that the corroded areas were covered with corrosion products such as $\mathrm{CuCl}_{2} \cdot 3 \mathrm{Cu}(\mathrm{OH})_{2}$ and $\mathrm{SnO}^{28)}$. In particular, an increase in the corrosion current density on the amalgam clearly increased the area of corrosion as the surface area ratio of titanium increased.

Similar to the conventional amalgam, the high-copper amalgam also showed a significant decrease in the amount of released mercury ions when the amalgam contacted with titanium at any surface area ratio. This phenomenon might be ascribed to the same causes as suggested for the conventional amalgam. Probably, the corrosion products on the corroded areas and adsorption of mercury ions on the titanium surface mainly lead to a decrease in the amount of the mercury ions. According to surface analysis using WDS, some tin but no mercury could be found on the titanium surface at any surface area ratio. As reported previously, this result suggests that mercury would have evaporated or that it would exist under thick corrosion products even if mercury had adsorbed on the titanium surfaces. Even if the mechanism of decrease in the amount of released mercury ions were assumed, surface analysis would not be sufficient to explain it. 


\section{CONCLUSIONS}

1. When the surface area ratio of titanium grew at $=10 / 1$, tin ions and copper ions released from the conventional amalgam and the high-copper amalgam, respectively, markedly increased compared with those of the amalgams not in contact with titanium. Such a large surface area ratio of titanium possibly led to heavy corrosion of the amalgams.

2. Contact with titanium at any surface area ratio decreased the amount of mercury ions released from the conventional amalgam and the high-copper amalgam.

3. A macroscopic observation using SEM with WDS showed that the conventional amalgam surface was evenly corroded similar to the "general corrosion" irrespective of contact with titanium. As the surface area ratio of titanium grew, the distribution of tin increased everywhere on the surface of the conventional amalgam in contact with titanium, but those of silver and mercury decreased.

4. The same observation showed that the high-copper amalgam surface locally corroded in the vicinity of the small pits irrespective of contact with titanium. As the surface area ratio of titanium grew, the corroded areas also became large. The distributions of tin increased, but those of silver and mercury decreased on the corroded areas, as in the case of the conventional amalgam.

\section{ACKNOWLEDGEMENTS}

The authors greatly acknowledge the Industrial Technology Institute of Miyagi Prefectural Government for allowing use of the inductively coupled plasma atomic emission spectrometry analyzer. Thanks are also due to Dr. Katuhiko Asami and Dr. Asahi Kawashima of the Institute for Metal Research, Tohoku University for their help with the surface analyses. This study was partially supported by the grant KOSEF-9636 of JSPS RONPAKU Program.

\section{REFERENCES}

1) Holland, R. I.: Galvanic currents between gold and amalgam, Scand J Dent Res, 88 : 269$272,1980$.

2) Chen, C. P.W. and Greener, E. H.: A galvanic study of different amalgams, J Oral Rehabil, $4: 23-27,1977$.

3) Johansson, B. I.: An in vitro study of galvanic currents between amalgam and gold alloy electrodes in saliva and in saline solutions, Scand J Dent Res, 94:562-568, 1986.

4) Marek, M.: Interactions between dental amalgams and the oral environment, Adv Dent Res, 6 : 100-109, 1992.

5) Johansson, C. and Moberg, L. E.: Area ratio effects on metal ion release from amalgam in contact with gold, Scand J Dent Res, $99: 246-253,1991$.

6) Takada, Y.: Corrosion resistance of dental alloys evaluated from released ions, Corrosion Engineering, $49: 669-685,2000$.

7) Reclaru, L. and Meyer, J. M.: Study of corrosion between a titanium implant and dental alloys, J Dent, $22:$ 159-168, 1994.

8) Yamaoka, M.: Electrochemical studies on contact between dissimilar metals. The 
contact potential and contact current of various metals, Nihon Univ Dent J, 68:390-401, 1994. (in Japanese)

9) Ravholt, G.: Corrosion current and $\mathrm{pH}$ rise around titanium coupled to dental alloys, Scand J Dent Res, 96 : 466-472, 1988.

10) Johansson, B. I. and Bergmanet, B.: Corrosion of titanium and amalgam couples. Effect of fluoride, area size, surface preparation, and fabrication procedure, Dent Mater, 11 : 41-46, 1995.

11) Horasawa, N., Takahashi, S., and Marek, M.: Galvanic interaction between titanium and gallium alloy or dental amalgam, Dent Mater, 15 : 318-322, 1999.

12) Anusavice, K. J.: Philips' Science of Dental Materials, 10th ed., WB. Saunders Co. Inc., Philadelphia, 1996, pp.361-385.

13) O'Brien, W. J.: Dental Materials and Their Selection, 2nd ed., Quintessence Publishing Co., Inc., Chicago, 1997, pp.190-191.

14) Craig, R. G.: Restorative Dental Materials, $10^{\text {th }}$ ed., Mosby, St. Louis, 1997, pp.209-243.

15) Espevik, S.: In vitro corrosion of dental amalgams with different $\mathrm{Cu}$ content, Scand $J$ Dent Res, 85 : 631-636, 1977.

16) Mateer, R.S. and Reitz, D.: Galvanic degradation of amalgam restorations, $J$ Dent Res, 51(6) : 1546-1551, 1972.

17) Yamanaka, S., Ohta, K., Nomura, T., Suzuki, K., and Takaesu, Y.: The lymphocyte simulation test in vitro as a screening method for allergy associated with dental metals, $J$ Dent Health, $51: 69-76,2001$. (in Japanese)

18) Yamanaka, S., Ohta, K., Takayanagi, A., Nomura, T., and Takaesu, Y.: Evaluation of patch tests as a screening method for allergy associated with dental metals, $J$ Dent Health, $47: 27-35,1997$. (in Japanese)

19) Tanaka, K.: Corrosion mechanism of coupled dental alloys, Tohoku Univ Dent J, $14: 119$ 138, 1996. (in Japanese)

20) Takada, Y. and Okuno, O.: Reversing potentials and increasing amount of released ions with contact corrosion between stainless steels and Au-Ag-Pd alloys, $J J$ Dent Mater, 15 (6) : 525-531, 1996. (in Japanese)

21) Horasawa, N., Ito, M., and Takahashi, S.: Electrochemical stability of dental materials; Part 2. Released elements of dental alloys, $J J$ Dent Mater, 6(6) : 762-767, 1987. (in Japanese)

22) Yoshinari, M., Kaneko, T., and Sumii, T.: The influence of the anodic potential on metal-component dissolution from dental alloys -Comparison with the static immersion test-, $J$ J Dent Mater, 11(3): 515-526, 1992. (in Japanese)

23) Okabe, T., Mitchell, R., Butts, B., and Fairhurst, C. W.: A study of high copper amalgams: 3. SEM observations of amalgamation of high copper powders, $J$ Dent Res, 57 : 975-982, 1978.

24) Ogletree, R. H. and Marek, M: Effect of mercury on corrosion of $\eta^{\prime}$ Cu-Sn phase in dental amalgams, Dent Mater, $11: 332-336,1995$.

25) Onagawa, J. and Abe, T.: Corrosion behavior of high copper amalgam, $J J$ Dent Mater, 22(59): 157-161, 1981. (in Japanese)

26) Sarker, N. K. and Greener, E. H.: Electrochemistry of the saline corrosion of conventional dental amalgams, J Oral Rehabil, 2 : 49-62, 1975.

27) Lemaitre, L., Moors, M., and Van Peteghem, A. P.: A mechanistic study of the electrochemical corrosion of the $\gamma_{2}$ phase in dental amalgams: II. Introduction of a model, $J$ Oral Rehabil, $16: 543-548,1989$.

28) O'Brien, W. J.: Dental Materials and Their Selection, 2nd ed., Quintessence Publishing Co., Inc., Chicago, 1997, pp.193-194.

29) Greener, E. H. and Matsuda, K.: Effect of oxygen on the corrosion of dental amalgam, J Oral Rehabil, $12: 123-133,1985$.

30) Marek, M.: The release of mercury from dental amalgam: The mechanism and in vitro testing, J Dent Res, $69: 1167-1174,1990$. 
31) Holland, R. I.: Release of mercury vapor from corroding amalgam in vitro, Dent Mater, 9 : 99-103, 1993.

32) Takada, Y., Asami, K., Kawashima, A., Hanawa, T., and Okuno, O.: Adsorption of metallic ions on titanium surface in a simulated oral cavity, $J J$ Dent Mater, 20 Special Issue $37: 128-128,2001$. (in Japanese) 